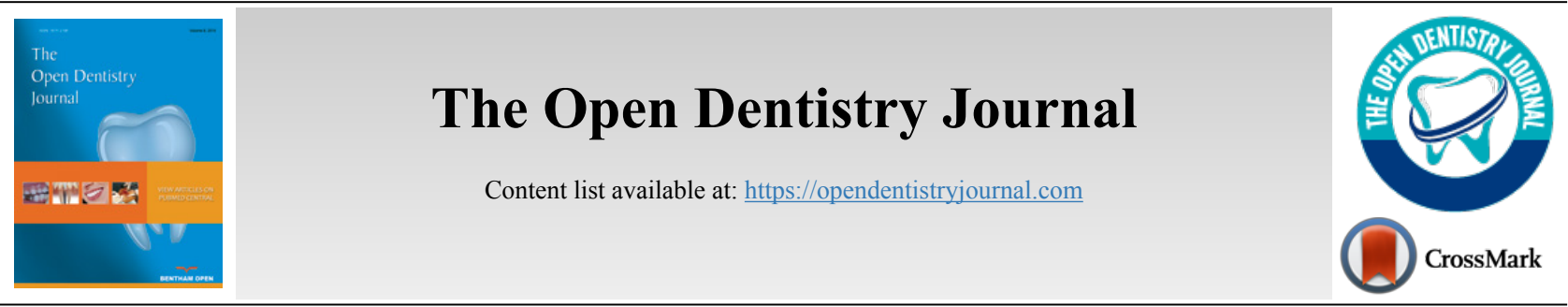

RESEARCH ARTICLE

\title{
Endodontic Treatment versus Implant Placement for Compromised Teeth: Decision-Making Trends in Saudi Arabia
}

\author{
Rayan Bahabri ${ }^{1,3, *}$, Sary Borzangy ${ }^{2}$, Nevine Taymour $^{3,4}$, Abdulrahman Maddhar ${ }^{1}$, Mahmod Alkayyal $^{1}$, Walaa Alhazmi $^{1}$ \\ and Sarah Taher ${ }^{1}$ \\ ${ }^{1}$ Taibah University Dental College and Hospital, Al-Madinah Al-Munawarah 42353, Saudi Arabia \\ ${ }^{2}$ Department of Substitutive Dental Sciences, Taibah University Dental College and Hospital, Al-Madinah Al-Munawarah 42353, Saudi Arabia \\ ${ }^{3}$ Department of Restorative Dental Sciences, Taibah University Dental College and Hospital, Al-Madinah Al-Munawarah 42353, Saudi Arabia \\ ${ }^{4}$ Alexandria University, Alexandria, Egypt
}

\begin{abstract}
:
Background:

The decision to save a compromised tooth is a major challenge among dentists and may vary among those with different areas of specialization.

Objective:

The objective of this study was to determine the influencing factors that play a role in decision-making trends when choosing whether or not to save a compromised tooth, either through endodontic treatment or extraction and implant placement.

Methods:

In this cross-sectional study, a questionnaire was administered to a convenience sample to assess decision-making within different dental specialties among various dental schools in Saudi Arabia. Participants were stratified into four groups based on clinical specialties, including endodontists $(n=45,23.9 \%)$, periodontists $(n=51,27.1 \%)$, prosthodontists $(n=55,29.3 \%)$, and oral and maxillofacial surgeons $(n=37,19.7 \%)$. The data of 188 participants were analyzed using Chi-square tests, with significance at $\mathrm{p} \leq 0.05$.

Results:

Endodontists were significantly more likely than other specialists $(p \leq 0.002)$ to decide to retain a compromised tooth rather than place an implant. In difficult prosthetic cases, faculty surgeons were significantly more likely to place an implant than other specialists $(\mathrm{p} \leq 0.01)$.

Conclusion:

The assessment of decision-making trends demonstrated that retention of the natural tooth by endodontic and restorative treatments was preferred over extraction and implant placement. Increased prosthetic complexity shifted this preference towards implant placement. This study provides a basis to help identify factors contributing to decision-making among dental professionals; these factors could improve existing guidelines to ensure a successful practice.
\end{abstract}

Keywords: Decision-making, Endodontist, Evidence-based practice, Prognosis, Prostheses, Implants.

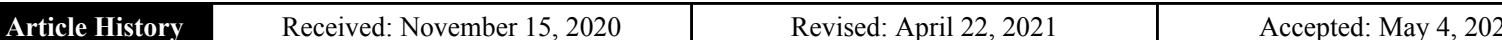

\section{INTRODUCTION}

Professionally performed root canal treatments and restorations to save a compromised tooth have been shown to have a high success rate [1]. However, the introduction of

"Address correspondence to this author at the Taibah University Dental College and Hospital, Al-Madinah Al-Munawarah, 42353, Saudi Arabia;

E-mail: rayanhb@gmail.com dental implants has changed perspectives related to some treatment modalities. Implant therapy involves the extraction and replacement of a missing tooth with a dental implant; this is an efficient treatment, with substantial success rates in terms of maintaining oral health status, function, and desired esthetics [2]. In fact, both treatment modalities constitute the cornerstone of dental therapy, each with its pros and cons, with various implications [3, 4]. Historically, the clinical situation has been 
more challenging when dentists have had to deal with a compromised tooth while maintaining safety measures [5]. In this respect, the selection of an appropriate treatment modality has been a difficult decision to make, particularly when advances have made it possible to save a compromised tooth $[6,7]$.

Deciding whether to retain a compromised tooth through an endodontic and restorative treatment or to undergo extraction and implant placement remains an issue in need of resolution among dentists, especially those of the academic dental community in Saudi Arabia, where there is no clinical consensus on how to best treat these issues. Therefore, this study aimed to investigate the decision-making trends of academic faculty, all of whom were practicing dentists with different clinical specialties and educational degrees from dental schools in Saudi Arabia. Specifically, the study aimed to determine whether dental professionals would attempt to save and retain a compromised tooth through root canal treatment or whether they would decide to perform an extraction and implant placement. The study also aimed to determine the factors involved in the selection of an appropriate treatment modality.

\section{MATERIALS AND METHODS}

\subsection{Setting}

A cross-sectional, descriptive, survey-based study was conducted nationwide in Saudi Arabia. The data did not contain any personal identifiers, nor were data from vulnerable groups included. Before the study was conducted, ethical approval was obtained from Taibah University College of Dentistry Research Ethics Committee (TUCDREC) (study reference No: TUCDREC/2018118/Maddhar). The TUCDREC is organized and operated in accordance with the Saudi National Regulation of the National Bioethics Committee, the Guidelines of the Declaration of Helsinki, the International Conference of Harmonization (ICH), and the United States Code of Federal Regulations. The study was conducted from January 2018 to March 2019.

\subsection{Study Population}

All participants enrolled in this study were academic faculty members from all the dental schools in Saudi Arabia. Participants were specialists in one of four areas (endodontists, periodontists, prosthodontists, and maxillofacial oral surgeons), performing various treatment procedures as part of their clinical specialty and academic education. Based on information obtained from universities' websites, 306 dentists were contacted.

\subsection{Sample Type and Size}

Convenience sampling was used to collect data from specialists from all the dental schools participating in this study; the participants were stratified into four main groups based on the clinical specialty of the faculty members. In addition, based on the number of clinical years of experience, three main groups were used for stratification $(<10,10-19, \geq$ 20 years); based on postgraduate education, two groups were compared (those with a doctoral degree and clinical certificate, and those with a master's degree and clinical certificate). The sample size was calculated using a tool provided online by the US Centers for Disease Control and Prevention (CDC) at a confidence level of $95 \%$; the required sample size was determined to be 187 participants [8].

\subsection{Inclusion and Exclusion Criteria}

Out of 306 dentists, 188 participants completed and anonymously returned the questionnaire and were included in this study, whereas $118 \mathrm{did}$ not and were excluded; this led to a final response rate of $61 \%$.

\subsection{Assessment Procedure}

The research tool used was a reliable, close-ended dichotomous questionnaire that has been previously validated and used in a study published by Di Fiore et al. [1], with slight modifications to fulfill all the requirements needed to assess all aspects of the current study. The questionnaire was distributed online to all dental schools in the country and was provided to some universities in print to obtain a sample of academic dentists with different specialties. The questionnaire was designed to ask participants about their preferred treatments for clinical scenarios that were described and supported by radiographs. All participants were invited to complete the questionnaire on a voluntary basis.

\subsection{Components of the Questionnaire}

The questionnaire was composed of five sections. Section I consisted of an introductory page, which explained the aims and objectives of the study and confirmed that all the information provided would remain anonymous and confidential. Section II assessed participants' demographic information, including sex, specialty, years of clinical experience, and postgraduate degree achieved. Section III described two treatment options, either root canal treatment and restoration (treatment option A) or extraction and dental implant placement (treatment option B). Section IV comprised eighteen clinical scenarios for which participants were asked to indicate which of the two treatment choices they would select, either A or B. Clinical scenarios were categorized based on either prosthetic or endodontic complexity. Based on prosthetic complexity, the following three categories were used for classification: simple complexity (single tooth, questions 1-6), intermediate complexity (multiple teeth, questions 7-12), and advanced complexity (abutments for a fixed prosthesis, questions 13-18); abutments are teeth supporting prosthesis that are at either side of the edentulous space. Based on endodontic complexity, the following five levels were used for classification: level one (questions 1, 7, and 13), level two (questions 4, 10, and 15), level three (questions 2, 5, 8, 11, 14, 16), level four (questions 3 and 9), and level five (questions 6 , $12,17,18)$. Section $V$ included four questions regarding the general medical condition of patients, the position of the tooth in the oral cavity, the treatment of a canine tooth, and the preferred replacement method for a single missing tooth. 


\subsection{Data Collection and Analysis}

Data were collected using an electronic questionnaire (Google Forms) as well as paper printouts; the data were cleaned to remove outliers or odd figures. Descriptive analysis of the data to determine frequencies and percentages was followed by suitable inferential statistics using the Chi-square test; $\mathrm{p} \leq 0.05$ was deemed statistically significant. Data were analyzed using IBM Statistical Package for the Social Sciences (SPSS) software (version 21, Armonk, New York, USA).

\section{RESULTS}

\subsection{Sample Characteristics}

A total of 188 faculty participants were stratified into four main groups based on their clinical specialty. The highest response rate was found among prosthodontists $(\mathrm{n}=55$, $29.3 \%)$, followed by periodontists $(\mathrm{n}=51,27.1 \%)$, endodontists $(n=45,23.9 \%)$, and oral and maxillofacial surgeons $(n=37,19.7 \%)$. Of these, $67 \%$ of participants were male $(n=126)$ and $33 \%$ were female $(n=62)$. Based on clinical experience, the highest response rate was observed among a group of participants with 10-19 years of experience $(\mathrm{n}=84,44.7 \%)$, followed by those with less than 10 years of experience $(\mathrm{n}=74,39.4 \%)$; the lowest response rate was among participants with 20 years of experience or more $(\mathrm{n}=$ $30,16 \%$ ). Furthermore, based on postgraduate education, the highest response rate was found among participants with a doctoral degree and clinical certificate $(n=118,62.8 \%)$, followed by those with a master's degree and clinical certificate $(\mathrm{n}=70,37.2 \%)$.

\subsection{Treatment Selection Based on Prosthetic Treatment Complexity}

In response to questions that were grouped based on prosthetic treatment complexity (Table 1), the faculty participants were in favor of tooth retention $(\mathrm{n}=188,65.0 \%)$ rather than implant placement $(\mathrm{n}=188,35 \%)$. This treatment option was selected at significantly higher rates among endodontists compared with the other participant groups $(77.6 \%, \mathrm{p}<0.05)$. Endodontists indicated that they would select treatment A (root canal and restorative treatment) for simple, intermediate, and complex prosthetic cases at a higher rate $(n=45,77.6 \%)$ than all other participant groups; however, no statistically significant difference $(\mathrm{p}=0.06)$ was observed when compared with prosthodontists $(\mathrm{n}=55,61.6 \%)$. Oral and maxillofacial surgeons, on the other hand, selected treatment $B$ (extraction and dental implant placement) for compromised, simple, and complex prosthetic cases; this group chose treatment $B(n=37,46.4 \%)$ at a significantly higher rate than specialists from all other groups $(\mathrm{p} \leq 0.01)$.

\subsection{Treatment Selection Based on Endodontic Treatment Complexity}

Based on questions related to endodontic treatment complexity (Table 2), all groups indicated they would select treatments favoring tooth retention $(\mathrm{n}=188,61.7 \%)$ over implant placement $(\mathrm{n}=188,38.3 \%)$. Endodontists selected treatment $\mathrm{A}$ for each of the five levels of endodontic complexity. The overall response rate of endodontists ( $n=45$, $75.2 \%$ ) was higher than that of all other groups; the rate was significantly higher $(\mathrm{p} \leq 0.04)$ than that of oral and maxillofacial surgeons $(n=37,49.8 \%)$.

Table 1. Treatment selection among specialties based on prosthetic treatment complexity $(n=188)$.

\begin{tabular}{|c|c|c|c|c|c|c|}
\hline $\begin{array}{l}\text { Prosthetic Treatment Complexity } \\
\text { (Question Number) }\end{array}$ & $\begin{array}{c}\text { Treatment } \\
\text { choice }^{*}\end{array}$ & \begin{tabular}{|c|} 
Endodontist \\
$\mathrm{n}=45(23.9 \%)$
\end{tabular} & $\begin{array}{c}\text { Periodontist } \\
\mathrm{n}=51(27.1 \%)\end{array}$ & $\begin{array}{l}\text { Prosthodontist } \\
\mathrm{n}=55(29.3 \%)\end{array}$ & $\begin{array}{c}\text { Oral and Maxillofacial } \\
\text { Surgeon } \\
\mathbf{n}=\mathbf{3 7}(\mathbf{1 9 . 7 \% )}\end{array}$ & Total \\
\hline \multirow{2}{*}{$\begin{array}{l}\text { Simple prosthetic cases (1-6; individual } \\
\text { teeth) }\end{array}$} & A & $74 \%$ & $68 \%$ & $61 \%$ & $44 \%$ & $3 \%$ \\
\hline & B & $26 \%$ & $32 \%$ & $39 \%$ & $56 \%$ & $8 \%$ \\
\hline \multirow{2}{*}{$\begin{array}{l}\text { Intermediate prosthetic cases } \\
\quad(7-12 ; \text { multiple teeth })\end{array}$} & A & $89 \%$ & $79 \%$ & $76 \%$ & $71 \%$ & $9 \%$ \\
\hline & B & $11 \%$ & $21 \%$ & $24 \%$ & $29 \%$ & $1 \%$ \\
\hline \multirow{2}{*}{$\begin{array}{l}\text { Difficult prosthetic cases } \\
\text { (13-18; abutment teeth) }\end{array}$} & A & $70 \%$ & $55 \%$ & $48 \%$ & $46 \%$ & $5 \%$ \\
\hline & $\mathrm{B}$ & $30 \%$ & $45 \%$ & $52 \%$ & $54 \%$ & $5 \%$ \\
\hline \multirow{2}{*}{$\begin{array}{l}\text { Overall } \\
\text { (Q 1-18) }\end{array}$} & $\mathrm{A}$ & $77.6 \%$ & $67.3 \%$ & $61.6 \%$ & $53.6 \%$ & $65 \%$ \\
\hline & B & $22.4 \%$ & $32.7 \%$ & $38.4 \%$ & $46.4 \%$ & $35 \%$ \\
\hline
\end{tabular}

*Treatment A: root canal and restorative treatment; treatment B: extraction and dental implant placement.

Table 2. Treatment selection among specialties based on endodontic treatment complexity $(n=188)$.

\begin{tabular}{|c|c|c|c|c|c|c|}
\hline $\begin{array}{c}\text { Endodontic Treatment } \\
\text { Complexity } \\
\text { (Question Number) }\end{array}$ & Treatment Choice* & \begin{tabular}{|c|} 
Endodontist \\
$\mathrm{n}=\mathbf{4 5}(23.9 \%)$
\end{tabular} & $\begin{array}{c}\text { Periodontist } \\
n=51(27.1 \%)\end{array}$ & $\begin{array}{l}\text { Prosthodontist } \\
\text { n }=55(29.3 \%)\end{array}$ & $\begin{array}{c}\text { Oral and Maxillofacial Surgeon } \\
\qquad \mathbf{n}=\mathbf{3 7}(\mathbf{1 9 . 7 \% )}\end{array}$ & Total \\
\hline \multirow{2}{*}{$\begin{array}{l}\text { Level one } \\
(1,7,13)\end{array}$} & $\mathrm{A}$ & $79 \%$ & $70 \%$ & $65 \%$ & $57 \%$ & $68 \%$ \\
\hline & B & $21 \%$ & $30 \%$ & $35 \%$ & $43 \%$ & $32 \%$ \\
\hline \multirow{2}{*}{$\begin{array}{l}\text { Level two } \\
(4,10,15)\end{array}$} & A & $79 \%$ & $66 \%$ & $59 \%$ & $55 \%$ & $65 \%$ \\
\hline & B & $21 \%$ & $34 \%$ & $41 \%$ & $45 \%$ & $35 \%$ \\
\hline \multirow{2}{*}{$\begin{array}{c}\text { Level three } \\
(2,5,8,11,14,16)\end{array}$} & A & $92 \%$ & $82 \%$ & $76 \%$ & $69 \%$ & $80 \%$ \\
\hline & B & $8 \%$ & $18 \%$ & $24 \%$ & $31 \%$ & $20 \%$ \\
\hline
\end{tabular}




\begin{tabular}{|c|c|c|c|c|c|c|}
\hline $\begin{array}{c}\text { Endodontic Treatment } \\
\text { Complexity } \\
\text { (Question Number) }\end{array}$ & Treatment Choice* & $\begin{array}{c}\text { Endodontist } \\
n=45(23.9 \%)\end{array}$ & $\begin{array}{c}\text { Periodontist } \\
\mathrm{n}=51(27.1 \%)\end{array}$ & $\begin{array}{l}\text { Prosthodontist } \\
\mathrm{n}=55(29.3 \%)\end{array}$ & $\begin{array}{c}\text { Oral and Maxillofacial Surgeon } \\
\mathbf{n}=\mathbf{3 7}(\mathbf{1 9 . 7 \% )}\end{array}$ & Total \\
\hline \multirow{2}{*}{$\begin{array}{l}\text { Level four } \\
(3,9)\end{array}$} & $\mathrm{A}$ & $64 \%$ & $44 \%$ & $42 \%$ & $28 \%$ & $45 \%$ \\
\hline & $\mathrm{B}$ & $36 \%$ & $56 \%$ & $58 \%$ & $72 \%$ & $55 \%$ \\
\hline \multirow{2}{*}{$\begin{array}{c}\text { Level five } \\
(6,12,17,18)\end{array}$} & $\mathrm{A}$ & $62 \%$ & $56 \%$ & $48 \%$ & $40 \%$ & $52 \%$ \\
\hline & $\mathrm{B}$ & $38 \%$ & $44 \%$ & $52 \%$ & $60 \%$ & $48 \%$ \\
\hline \multirow{2}{*}{$\begin{array}{l}\text { Overall } \\
(1-18)\end{array}$} & $\mathrm{A}$ & $75.2 \%$ & $63.6 \%$ & $58 \%$ & $49.8 \%$ & $61.7 \%$ \\
\hline & $\mathrm{B}$ & $24.8 \%$ & $36.4 \%$ & $42 \%$ & $50.2 \%$ & $38.3 \%$ \\
\hline
\end{tabular}

*A: root canal and restorative treatment; B: extraction and dental implant placement.

Table 3. The response percentage of the study participants to special conditions $(n=188)$.

\begin{tabular}{|c|c|c|c|c|c|}
\hline Question Number) & Treatment Choice* & $\begin{array}{c}\text { Endodontist } \\
\mathbf{n = 4 5 ( 2 3 . 9 \% )}\end{array}$ & $\begin{array}{c}\text { Periodontist } \\
\mathbf{n = 5 1 ( 2 7 . 1 \% )}\end{array}$ & $\begin{array}{c}\text { Prosthodontist } \\
\mathbf{n = 5 5 ( 2 9 . 3 \% )}\end{array}$ & $\begin{array}{c}\text { Oral and Maxillofacial Surgeon } \\
\mathbf{n = 3 7}(\mathbf{1 9 . 7} \%)\end{array}$ \\
\hline \multirow{2}{*}{$1-3$} & $\mathrm{~B}$ & $34 \%$ & $32 \%$ & $24 \%$ & $32 \%$ \\
\cline { 2 - 6 } & $\mathrm{A}$ & $66 \%$ & $68 \%$ & $76 \%$ & $68 \%$ \\
\hline \multirow{2}{*}{4} & Fixed 3-unit bridge & $11.1 \%$ & $13.7 \%$ & $16.4 \%$ & $10.8 \%$ \\
\cline { 2 - 6 } & Single implant & $88.9 \%$ & $86.3 \%$ & $83.6 \%$ & $80 \%$ \\
\hline
\end{tabular}

*No: extraction and dental implant placement; Yes: root canal and restorative treatment.

\subsection{Treatment Selection for Special Cases}

The response rates of the four groups of participants to the four questions that were related to special clinical conditions are presented in Table 3. The participants of all four groups indicated that they were more likely to choose treatment $\mathrm{A}(\mathrm{n}=$ $188,70 \%)$ than treatment $\mathrm{B}(\mathrm{n}=188,30 \%)$ to treat cases described in the special clinical scenarios; these situations included cases in which patients were medically compromised, cases in which the position of the tooth in the arch made treatment difficult, and cases requiring the treatment of a canine tooth. In patients with a complicated medical history, endodontists were more likely to choose this treatment option $(\mathrm{n}=45,78.5 \%)$ than the other groups, although the rates were not significantly different $(\mathrm{p}=0.668)$. A greater percentage of prosthodontists $(n=55,84.4 \%)$. Prosthodontists indicated that the anterior or posterior position of the tooth in the arch would influence their treatment selection in favor of tooth retention; although this rate was higher than that of the other groups, they did not significantly differ $(\mathrm{p}=0.971)$. A higher response rate was also found among prosthodontists $(\mathrm{n}=55,65.5 \%)$; that group indicated that a canine tooth would influence their choice of treatment in favor of tooth retention more than the other groups, although there was no statistically significant difference $(p=0.059)$.

However, in cases requiring the replacement of a single missing tooth, all the participants in this study indicated they would decide to place an implant rather than a fixed prosthesis. A higher response rate was reported among oral and maxillofacial surgeons $(n=37,89.2 \%)$ than other groups, although there was no statistically significant difference $(\mathrm{p}=$ $0.839)$.

\section{DISCUSSION}

This study provides important information regarding the current decision-making trends of academic faculty who are practicing dentists in Saudi Arabia. The findings pertain to the appropriate management of compromised teeth, either through retention with endodontic and restorative treatment or by extraction and implant placement. These trends should be taken into consideration in certain clinical scenarios in which the general systemic health status of the patient is of much concern. This is the first study conducted in Saudi Arabia to consider the decision-making of academic dentists; previous studies to date have been limited and have not been representative of the entire academic community in the kingdom.

The current study focused mainly on two issues. The first pertained to how best to manage compromised teeth when confronted with various levels of prosthetic and endodontic complexity. The second issue pertained to special considerations inherent to the proper means of managing compromised teeth in certain scenarios.

In the first part of this study, the general preference of dental faculty was to save and maintain compromised teeth that could otherwise be restorable at any level of prosthetic and endodontic complexity, even with the knowledge that some difficulty in treatment might be encountered. These findings are supported by those in the literature in which most dentists were fundamentally more inclined to save a tooth than to place an implant, even when it was not always convenient under all clinical conditions $[1,4,5]$.

However, based on the prosthetic clinical scenarios presented in the current study and the preference expressed by the oral and maxillofacial faculty surgeons, implants were considered the ideal treatment option over more conservative procedures in simple and advanced prosthetic cases that include single compromised teeth and multiple abutments planned for a fixed prosthesis. The preference among this group for placing implants in these cases was consistent with the literature. Many studies have demonstrated that due consideration should be given to certain key issues that vary based on the clinical situation; in some cases, placing an implant is deemed to be a necessary procedure $[4,7,9,10$, 12]. In cases of intermediate prosthetic complexity involving 
multiple compromised adjacent teeth, endodontic treatment was considered by all the faculty participants in this study to be a better therapeutic approach than implant placement. The rationale for this decision-making process is based on the level of treatment complexity and is supported by the dental literature; it might be a better choice to save and retain the tooth in question than to sacrifice it, provided that it can be restored $[13,14]$.

The second part of this study focused on special clinical considerations that were likely to influence the treatment choice of the faculty participants. Such difficult situations included patients with a complicated medical history, the position of the tooth in the arch that could make treatment difficult, the treatment of a canine tooth, and cases requiring the replacement of a single tooth. In situations with high complexity, all dental faculty in this study selected what they believed to be the most appropriate measures to rehabilitate the tooth in question through endodontic and restorative treatment over extraction and implant placement; these results were supported by previous studies $[1,5,13]$. On the other hand, in the case of replacing a single missing tooth, all faculty participants in the current study preferred to place an implant rather than a fixed prosthesis, as placing an implant in this situation would be a safer procedure than the unnecessary loss of sound tooth structures as a result of fixed prosthetic restoration; this finding is also supported by the literature [2, 15]. In a similar context, the present findings coincided with the preference expressed by patients in a previous survey study, which indicated that an implant-supported crown was a better therapeutic solution for the replacement of a single missing tooth, regardless of the location of the single space within the mouth [16].

Accordingly, the results obtained in this study could be rationally explained by some factors that influence decisionmaking that have been described in the literature, one of these being that it is always a better choice, biologically and functionally, to save a tooth rather than to replace it with an implant, especially when the restoration is possible [13]. It is also important to understand that the physical, biomechanical, and biological properties of natural teeth cannot be totally reproduced by implants and prosthetic restorations [17]. Therefore, the decision-making process of clinicians should always consider certain factors that affect the likelihood of treatment success and patient satisfaction $[15,16]$.

One of the limitations of this study was the fact that the sample was selected from among academic faculty members; this may limit the generalizability of the results, as they do not represent the entire dental community. This would be a great area of further research.

\section{CONCLUSION}

The decisions made by the dental professionals in this study were based on their high educational background, clinical experience, and the complexity of treatment. Current findings indicate that saving compromised teeth through retention with endodontic and restorative procedures is preferred over implant placements. Nevertheless, there is an increased potential for implant placement as prosthetic complexity increases; implant placement was most often preferred in single tooth replacement scenarios. Due consideration should be given to assess the restorability of the tooth in question, as well as the esthetic implications, clinical complexity, the position of the tooth in the arch, the general systemic health status of the patient, and the patient's overall satisfaction with a procedure. Failure to recognize any of these parameters may negatively influence either the outcome of endodontic therapy or the survival of dental implants. The present study provides a snapshot of clinical perceptions from endodontic and prosthodontic perspectives; it may provide useful information to dental professionals to guide them in making the right decisions when choosing whether or not to try to save a tooth in their daily practices.

\section{ETHICS APPROVAL AND CONSENT TO PARTICIPATE}

Ethical approval was obtained from Taibah University College of Dentistry Research Ethics Committee (TUCDREC) (study reference No: TUCDREC/2018118/Maddhar).

\section{HUMAN AND ANIMAL RIGHTS}

No animals were used in this research. All human research procedures followed were in accordance with the ethical standards of the committee responsible for human experimentation (institutional and national) and with the Helsinki Declaration of 1975, as revised in 2013.

\section{CONSENT FOR PUBLICATION}

Informed consent was obtained from the participants prior to data collection.

\section{AVAILABILITY OF DATA AND MATERIALS:}

Not applicable.

\section{FUNDING}

None.

\section{CONFLICT OF INTEREST}

The authors declare no conflict of interest, financial or otherwise.

\section{ACKNOWLEDGEMENTS}

The authors would like to thank the people who helped with the data collection from all the universities in the country, including Dr. Wafa Alhazmi, Dr. Mohannad Alsihli, Anwar Alzahrani, Elyas Asiri, Sami Alresheedi, Abdulrzzaq Alghamdi, Remaz Ballaji, and Ahmed Taher. Special thanks and appreciation are extended to all the dental faculty members who participated in this research.

\section{REFERENCES}

[1] Di Fiore PM, Tam L, Thai HT, Hittelman E, Norman RG. Retention of teeth versus extraction and implant placement: Treatment preferences of dental faculty and dental students. J Dent Educ 2008; 72(3): 352-8. [http://dx.doi.org/10.1002/j.0022-0337.2008.72.3.tb04501.x] [PMID: 18316539]

[2] Brånemark PI, Adell R, Albrektsson T, Lekholm U, Lundkvist S, Rockler B. Osseointegrated titanium fixtures in the treatment of 
edentulousness. Biomaterials 1983; 4(1): 25-8.

[http://dx.doi.org/10.1016/0142-9612(83)90065-0] [PMID: 6838955]

[3] Doyle SL, Hodges JS, Pesun IJ, Law AS, Bowles WR. Retrospective cross sectional comparison of initial nonsurgical endodontic treatment and single-tooth implants. J Endod 2006; 32(9): 822-7.

[http://dx.doi.org/10.1016/j.joen.2006.06.002] [PMID: 16934623]

[4] Ikbal MK, Kim S. For teeth requiring endodontic treatment, what are the differences in outcomes of restored endodontically treated teeth compared to implant-supported restoeations? Int J Oral Maxillofac Implants 2007; 22(Suppl.): 96-116.

[5] Al-Qarni MA, Khader MA, Al-Sharif M, Al-Shahrani A. Retention and restoration "versus "extraction and implant:" A questionnaire survey among dentists in Asir Region, Kingdom of Saudi Arabia. J Int Oral Health 2015; 7(12): 105-9.

6] Baba NZ, Goodacre CJ, Kattadiyil MT. Tooth retention through root canal treatment or tooth extraction and implant placement: A prosthodontic perspective. Quintessence Int 2014; 45(5): 405-16. [PMID: 24634905]

[7] John V, Chen S, Parashos P. Implant or the natural tooth--A contemporary treatment planning dilemma? Aust Dent J 2007; 52(1)(Suppl.): S138-50.

[http://dx.doi.org/10.1111/j.1834-7819.2007.tb00521.x] [PMID: 17546868]

[8] Dean AG, Sullivan KM, Soe MM. OpenEpi: Open Source Epidemiologic Statistics for Public Health, Sample Size for a Proportion or Descriptive Study https://www.openepi.com/Sample Size/SSPropor.htm

[9] Ratner BD. Replacing and renewing: Synthetic materials, biomimetics, and tissue engineering in implant dentistry. J Dent Educ 2001; 65(12): 1340-7.

[http://dx.doi.org/10.1002/j.0022-0337.2001.65.12.tb03493.x] [PMID: 11780652]

[10] Avila G, Galindo-Moreno P, Soehren S, Misch CE, Morelli T, Wang
H-L. A novel decision-making process for tooth retention or extraction. J Periodontol 2009; 80(3): 476-91.

[http://dx.doi.org/10.1902/jop.2009.080454] [PMID: 19254132]

[11] Ekelund J-A, Lindquist LW, Carlsson GE, Jemt T. Implant treatment in the edentulous mandible: A prospective study on Brånemark system implants over more than 20 years. Int J Prosthodont 2003; 16(6): 602-8.

[PMID: 14714838]

[12] Dawson AS, Cardaci SC. Endodontics versus implantology: To extirpate or integrate? Aust Endod J 2006; 32(2): 57-63. [http://dx.doi.org/10.1111/j.1747-4477.2006.00019.x]

[PMID: 16869944

[13] Vahdati SA, Torabinejad M, Handysides R, Lozada J. A retrospective comparison of outcome in patients who received both nonsurgical root canal treatment and single-tooth implants. J Endod 2019; 45(2): 99-103.

[http://dx.doi.org/10.1016/j.joen.2018.10.018] [PMID: 30711185]

[14] Al Shareef AA, Saad AY. Endodontic therapy and restorative rehabilitation versus extraction and implant replacement. Saudi Endod J 2013; 3(3): 107-13.

[http://dx.doi.org/10.4103/1658-5984.121502]

[15] Kan JYK, Rungcharassaeng K, Lozada J. Immediate placement and provisionalization of maxillary anterior single implants: 1-year prospective study. Int J Oral Maxillofac Implants 2003; 18(1): 31-9. [PMID: 12608666]

[16] Augusti D, Augusti G, Re D. Prosthetic restoration in the single-tooth gap: Patient preferences and analysis of the WTP index. Clin Oral Implants Res 2014; 25(11): 1257-64.

[http://dx.doi.org/10.1111/clr.12264] [PMID: 24021020]

[17] Goodacre CJ, Bernal G, Rungcharassaeng K, Kan JY. Clinical complications with implants and implant prostheses. J Prosthet Dent 2003; 90(2): 121-32

[http://dx.doi.org/10.1016/S0022-3913(03)00212-9] [PMID: 12886205]

(C) 2021 Bahabri et al.

This is an open access article distributed under the terms of the Creative Commons Attribution 4.0 International Public License (CC-BY 4.0), a copy of which is available at: https://creativecommons.org/licenses/by/4.0/legalcode. This license permits unrestricted use, distribution, and reproduction in any medium, provided the original author and source are credited. 